\title{
Un hombre, un libro
}

ECIÉN llegó a la ciudad el último libro de José Vasconcelos. Llámase sa Raza Cósmica. He aqui un motivo para escribir. mal hiladas, algunas notas sobre el ilustre hombre.

Pero el momento particular en que aparece esta obra requiere un aparte: se produce en América, alrededor de Vasconcelos, la más desusada polémica, mientras aquí mismo se le ataca con una porfía inexplicable. Inexplicable es la palabra justa. Lo seguirá siendo en tanto no pueda uno. por natural decoro de la inteligencia, explicarse la baja razón y el sentimiento sucio.

Digamos ahora, en són de comento definitivo. que no nos impresiona esa campaña contra Vasconcelos, asi la suscriban Lugones o Salado Alvarez, toutes proportions gardées. Las obras se destruyen con zapapicos o con obras, no con discursos engorrosos. ¿Dónde podremos examinar las del otro bando? Hay una: Santos Chocano asesinó a Elmore veinticuatro horas después de confesarse dentro de la moral inca, sno matar. no robar, no mentirs. Esto. naturalmente, no nos seduce. Tanto menos cuanto que su sola disculpa-la de ser un gran poeta-es inaceptable como verdad y como disculpa.

Y demos vuelta a la página pasional de una buena vez. Nos disgustaría producir, como los Salados y los Pugas, un concierto de ranas sobre la charca de una idea invariable.

\section{LA RAZA CÓSMICA, UNA PROFECIAA}

Llama José Vasconcelos raza cósmica a la posible resultante superior de las cuatro conocidas: roja, negra y amarilla-que 
terminaron su misión histórica-más la blanca que realiza actualmente la suya por el dominio de lo material. Misión, he aqui una palabra rica en sugerencias. Misión, cometido, supremo encargo que cada una de las razas cumple sobre la Tierra sin más propósito que dar una sintesis prodigiosa: la raza final, la perfecta. ¿Un sueño, tal vez? Tal vez si, pero en todo caso el sueño de siempre, aquel que nos impediría el pensamiento mismo si dejara de respaldarlo. La perfección. Asombra encontrarse, de repente, imposibilitado de concebir nada que no siguiese un oculto proceso de perfección, y es verdad sin embargo. El sueño viene a ser así como la esencia de todo pensamiento; pero éste de la raza cósmica es algo más, es una profecía.

El ocultismo, esa ciencia a lo absurdo de quien nadie osará reir. formuló ya la idea de una raza cósmica. Vasconcelos la acoge y la adapla a su visión personal. Los latinos de América-dice èl-ofrecen la substancia donde puede operarse la transformación, o sea la mezcla de sangres que repugna a los sajones y la parte más lecunda de la Tierra, el trópico. La raza blanca, dueña de lo material, dominará el calor como domina el frío. Trópico habitable querrá decir entonces la posibilidad de una civilización inesperáda.

Así es, tan mal como puedo yo decirlo, la profecia. Sólo que ésta, equipada al modo contemporáneo, no es la simple enunciación de un acontecimiento próximo, la enunciación del augur homérico o del profeta biblico, ronca de profundidad como si se pronunciase dentro de una caverna. Contiene, al contrario, su razón de ser en si misma. Esta razón se llama ley de los tres estados y consiste en derivar de dos estados sociales conocidos la necesidad lógica de un tercero en que los hombres se rijan por el sentimiento estético, por una suerte de spasión de bellezas. Dentro de estado semejante, la raza cósmica aparece coma una consecuencia natural, igualmente necesaria.

Pero el grito profético preside la concepción entera. Calla a veces, a veces se desborda y precipita. $\mathrm{Y}$ vemos a Vasconcelos-los ojos en un vacio fantástico-trazar las emigraciones. 
los campos de batalla, las ciudades nuevas... Vueltos al ambiente en que la palabra de los profetas es la sabiduría del pueblo, no sé qué anulación súbita de siglos nos traslada a los muros sagrados de Jerusalem.

\section{IBEROAMERICANISMO}

Vasconcelos profesa el iberoamericanismo. ¿.La Raza Cósmicas, cabe preguntar, procede de aquél? Yo digo que no. Vasconcelos es iberoamericanista porque cree en el destino de nuestra raza. De no ser así, la superioridad actual del sajón ocuparía sus mejores esfuerzos. Estará siempre, a pesar suyo. con el interés humano.

\section{LAS NOTAS DE VIAJES}

Las notas de viajes a la América del Sur ocupan la mayor parte del libro y son una manera de confirmar, robusteciéndola. la teoría de la raza cósmica.

Desde luego, queremos eludir en lo posible una apreciación literaria de las notas, y no porque dejen de resistir el análisis crítico, sino porque su misma lectura prueba la puerilidad de semejante empresa. Escritas con apremio y sin otro sostenido afán que revivir la memoria, esas notas contienen. sin embargo, páginas dignas de repasarse una y otra vez por el solo gusto de su belleza. El capítulo sobre la expedición al Iguazú se adentra en el tono poético, y llega a ser tan intenso, tan intimamente conmovido, que el poema de Pellicer no pudo captar más poesía. Así la visión de Río Janeiro desde el Pan de Azúcar. Asi otras muchas notas, donde' se advierte también un seguro instinto de la novela. ¿Para qué ocuparse. entonces, de la porción descuidada?

-La Raza Cósmica, es un libro de América. ¿Del río Bravo a la Patagonia? No, del inglés al español. Es, también, un libro 
de la juventud. Nosotros, los grandes, que bebimos el terrible veneno de ir a Paris, sentiriamos un gran alivio si se leyese a los niños. de Escuela el sueño de un hombre que, poseído de inspiración profética, adelantó el indice en la sombra para enseñarnos, palpitantes aún. las oscuras entrañas del destino. Ese hombre de inspiraciones. 